\title{
MODELAGEM MATEMÁTICA: RELATO DE UMA EXPERIÊNCIA
}

\begin{tabular}{|c|}
\hline Aparecida Gasquez Sousa 1; Márcia Rosa Uliana1 \\
1'nstituto Federal de Educação, Ciência e Tecnologia de Rondônia \\
aparecida.gasquez@ifro.edu.br - marcia.uliana@ifro.edu.br
\end{tabular}

Artigo submetido em 16/10/2012 e aceito em 20/11/2012.

\section{RESUMO}

O presente relato trata de uma situação de Modelagem Matemática que se desenvolveu de forma interdisciplinar, envolvendo conteúdos de matemática e de geografia, com uma turma de terceiro ano do curso Técnico em Agropecuária Integrado ao Ensino Médio, do Instituto Federal de Rondônia, Campus Colorado do Oeste. Esse estudo ocorreu nos meses de dezembro de 2011 e janeiro de 2012 e teve como objetivo promover a aprendizagem de estatística, bem como de questões referentes à fome no Brasil, de modo significativo e pautado em situações reais. Foi proposto e desenvolvido um trabalho de coleta e análise de dados dos custos e da origem (local de produção) dos itens que integram a cesta básica nas cidades de Colorado do Oeste, Buritis, Cerejeiras, Costa Marques e Porto Velho.
Colorado do Oeste apresentou o maior valor médio da cesta básica, $R \$ 231,49$, enquanto que Buritis apresentou o menor valor, $\mathrm{R} \$ 196,16$. Também foi possível obter o custo médio da cesta básica do estado de Rondônia, sendo que esse ficou entre os seis mais baixos quando comparado às localidades em que o DIEESE realiza pesquisa. Além dos resultados apresentados, esse trabalho contemplou os princípios de interdisciplinaridade e a contextualização dos conteúdos de matemática e de geografia, que são defendidos por estudiosos da educação como mecanismos que contribuem para o envolvimento e o interesse dos alunos nas atividades escolares.

PALAVRAS-CHAVE: Matemática; Modelagem Matemática; Estatística; Cesta básica.

\section{Mathematical modelling: a report of an experience}

\section{ABSTRACT}

This report is a situation that has developed mathematical modeling in an interdisciplinary, engaging content Mathematics and Geography, with a class of third year of a course in Agricultural Integrated Technical Rondônia's High School Federal Institute, Colorado do Oeste's campus. This study occurred EIXO, v. 1, n. 2
Colorado do Oeste had the highest average value of basic $R \$ 231.49$, while Buritis had the lowest value, which was $R \$ 196.16$. It was also possible to obtain the average cost of the basic basket of Rondônia State, and this was among the six lowest when compared with the localities in which the DIEESE conducts research. Included in 


\section{SOUSA; ULIANA (2012)}

from December 2011 until January 2012 and aims to promote the learning of Statistics and Financial Mathematics, as well as issues related to hunger in Brazil, significative and suported at real situations. To this end, we proposed to develop the work in collecting and analyzing the cost data and origin (local production) of the items that make up the basket of food at the cities: Colorado do Oeste, Buritis, Cerejeiras, Costa Marques and Porto Velho. addition to the results presented in this work are the principles of interdisciplinarity and contextualization of the contents of Geography and Mathematics, which are defended by education scholars, as mechanisms that contribute to the students' interest and involvement in school activities.

KEY-WORDS: Mathematics, Mathematical Modelling, Statistics, Basic Basket. 


\section{MODELAGEM MATEMÁTICA: RELATO DE UMA EXPERIÊNCIA}

\section{INTRODUÇÃO}

O processo de ensino-aprendizagem de matemática, no Brasil, sofreu influências e modificações consideráveis ao longo do século XX. Essas estão relacionadas aos avanços e às transformações do mundo moderno que trazem novas exigências aos educandos, em especial, aos do ensino médio. Nessa etapa da vida escolar, espera-se que os estudantes adquiram uma nova postura em relação ao conhecimento matemático, por meio do desenvolvimento de habilidades, e tornem-se capazes de "fazer matemática" através da construção de conceitos e procedimentos, formulação e resolução de problemas por si mesmos, bem como a partir da criação de situações cotidianas para o desenvolvimento do cálculo.

Na década de 1950, surgiu o Movimento da Matemática Moderna que acreditava ser possível expressar as ideias abstratas da matemática de maneira mais simples e coesa. Pautado no ensino da Lógica e na metodologia de Teoria dos Conjuntos, esse movimento perdurou até 1980. O foco desse movimento era a melhoria da aprendizagem, entretanto como essa não aconteceu de forma considerável, um novo movimento foi desencadeado: o da Educação Matemática (NERES, 2011).

Esse movimento se fundamenta em um ensino de matemática intercalando metodologias e recursos diferenciados. Nesse cenário, defende-se o uso de atividades investigativas, situações-problema, recursos da informática, atividades de Modelagem Matemática, jogos e recursos da etnomatemática, além de materiais concretos no processo de ensino-aprendizagem.

Abordaremos, neste trabalho de pesquisa, a Modelagem Matemática - uma metodologia de ensino que está obtendo destaque no âmbito da educação matemática. Essa maneira de ensinar começou a ser estudada e praticada, primeiramente, nos países da Europa e na América do Norte, sendo trazida para o Brasil na década de 1970, pelos professores Aristides C. Barreto, Ubiratan D’Ambrósio e Rodney C. Bassanezi, os quais participavam, na Europa, de encontros que discutiam a Modelagem Matemática como metodologia de ensino, conforme afirma Biembengut (2009).

A Modelagem Matemática é uma metodologia que pode ser utilizada no processo de ensino-aprendizagem da matemática nos diversos níveis de ensino. Ela passou a receber conceitos diferenciados, como o proposto por Barros (2009), que a caracteriza como sendo livre e espontânea e surge da necessidade de o homem em compreender os fenômenos que o cercam para interferir ou não em seu processo de construção. Já para Bassanezi (2006), educador matemático e autor de um dos poucos livros sobre o tema publicados no Brasil, a "modelagem matemática consiste essencialmente na arte de transformar problemas da realidade em problemas matemáticos e resolvê-los, interpretando suas soluções na linguagem do real" (BASSANEZI, 2006, p.16).

Apesar de essa metodologia ter chegado ao Brasil há 40 anos, não é muito difundida e utilizada nas aulas. Acredita-se que isso se deve à falta de conhecimento dos professores, pois os cursos de formação passaram a ofertá-la como uma disciplina, recentemente, há cerca de 10 anos. Ainda, como aponta o estudo de Barbosa (2004), muitas vezes a disciplina Modelagem Matemática é apenas informativa em vez de formativa. Os alunos passam a conhecê-la apenas de forma teórica e, pelo fato de não 


\section{SOUSA; ULIANA (2012)}

vivenciá-la ao longo da sua formação, não se sentem preparados e dispostos a utilizá-la em suas aulas, quando se tornam professores.

Vários estudos apontam problemas no ensino-aprendizagem da matemática na educação básica brasileira, como os realizados por Druck (2008), Gazire (2000), Salla (2012) e Perez (2004). Estes problemas, somados a outros fatores de diversas ordens, colocam o Brasil nas últimas posições do $\mathrm{PISA}^{1}$ em matemática, tornando-se necessário ousar e incorporar novas metodologias de ensino, a fim de reverter esse quadro. A modelagem é uma alternativa, pois possibilita um ensino em que os alunos são agentes ativos das aulas. Assim, os professores deixam de ser os detentores do conhecimento e passam a ser os mediadores entre a matemática, como ciência, e os alunos que necessitam conhecê-la para entender e resolver problemas do seu cotidiano.

A Modelagem Matemática atende aos preceitos da neurociência, pois esta defende que o desenvolvimento do cérebro decorre da integração entre o corpo e o meio social (ALMEIDA; VERTUAN, 2011). Para que isso de fato ocorra, o sujeito precisa ser motivado a envolver-se emocionalmente. A respeito disso, Salla (2012) diz que:

A escola deve ser um espaço que motive e não somente que se ocupe em transmitir conteúdos. Para que isso ocorra, o professor precisa propor atividades que os alunos tenham condições de realizar e que despertem a curiosidade deles e os faça avançar. É necessário leva-los a enfrentar desafios, a fazer perguntas e procurar respostas. (SALLA, 2012, p.52)

As Orientações Curriculares para o Ensino Médio (OCEM) defendem a Modelagem Matemática como uma opção metodológica para ensinar em sala de aula "que pode ser entendida como a habilidade de transformar problemas da realidade em problemas matemáticos e resolvê-los interpretando suas soluções na linguagem do mundo real." (BRASIL, 2006, p.84). Essa metodologia requer dos alunos envolvidos uma série de competências, tais como:

Selecionar variáveis que serão relevantes para o modelo a construir; problematizar, ou seja, formular o problema teórico na linguagem do campo matemático envolvido; formular hipóteses explicativas do fenômeno em causa; recorrer ao conhecimento matemático acumulado para a resolução do problema formulado, o que, muitas vezes, requer um trabalho de simplificação quando o modelo originalmente pensado é matematicamente muito complexo; validar, isto é, confrontar as conclusões teóricas com os dados empíricos existentes; e eventualmente ainda, quando surge a necessidade, modificar o modelo para que esse melhor corresponda à situação real, aqui se revelando o aspecto dinâmico da construção do conhecimento. (BRASIL, 2006, p.85)

Biembengut e Hein (2007) defendem a inserção de atividade de Modelagem Matemática no processo ensino-aprendizagem pelos seguintes motivos: aproxima outra área de conhecimento da matemática; enfatiza a importância da matemática para a formação do aluno; desperta o interesse pela matemática ante a aplicabilidade; melhora

\footnotetext{
${ }^{1}$ Programme for International Student Assessment - Programa Internacional de Avaliação de Alunos. O Brasil atingiu a colocação de $57^{\circ}$ em matemática, com nota 386 . O ranking é liderado pela China, que obteve pontuação média de 600. Disponível em http://educacao.uol.com.br/noticias/2010/12/07/pisa-2009em-matematica-pais-alcancou-57-colocacao.htm. Acesso em: 25 de set. 2012.
} 


\section{SOUSA; ULIANA (2012)}

a apreensão dos conceitos matemáticos; desenvolve a habilidade para resolver problemas e estimula a criatividade. Esses motivos foram os norteadores no desenvolvimento da atividade de modelagem matemática apresentada a seguir.

\section{Uma aplicação na sala de aula}

\subsection{0 contexto e a escolha do tema}

A experiência aqui relatada foi desenvolvida com um grupo de 29 alunos do terceiro ano do curso Técnico em Agropecuária Integrado ao Ensino Médio, do Instituto Federal de Educação, Ciência e Tecnologia de Rondônia, Câmpus Colorado do Oeste. Ocorreu durante os meses de dezembro de 2011 e janeiro de 2012 e teve como objetivo inicial promover a aprendizagem de estatística e de matemática financeira de modo significativo e pautado em situações reais.

Para tanto, a opção metodológica utilizada foi a Modelagem, pois "uma atividade de Modelagem Matemática tem em uma situação problemática a sua origem e tem como característica essencial a possibilidade de abarcar a cotidianidade ou a relação com aspectos externos à matemática" (ALMEIDA; VERTUAN, 2011, p. 22). Esses princípios subsidiaram a procura de um tema que possibilitasse trabalhar os conteúdos curriculares propostos de forma concreta e significativa para os estudantes.

Biembengut e Hein (2007) destacam que o tema pode ser escolhido pelo professor ou pelos alunos. Quando a escolha do tema é feita pelos alunos tem a vantagem de eles se sentirem mais participantes do processo, mas tem as desvantagens de o tema não ser adequado para desenvolver os conteúdos pretendidos no currículo ou, ainda, de ser muito complexo e o professor não dispor de tempo para explorá-lo.

Diante disso, o tema foi escolhido pela professora e trata sobre "O custo da cesta básica na cidade de Colorado do Oeste". A escolha se justifica pelo fato de os alunos possuírem residência fixa no município ou morarem, em regime de internato, no Câmpus. Para adquirirem os produtos de necessidade pessoal, esses alunos servem-se do comércio local, entretanto reclamam dos altos preços encontrados. Ainda, a escolha dessa temática possibilitaria explorar vários aspectos dos conteúdos matemáticos em questão, além de promover a investigação e comparação entre os preços de produtos em supermercados e cidades diferentes.

Pelo fato de a temática "cesta básica" ser muito ampla e não ser familiar aos alunos, a professora de Matemática optou por realizar a atividade em conjunto com a professora de geografia que exercia suas atividades docentes com o mesmo grupo de alunos. Assim, começaram a buscar mecanismos para o estudo da temática "cesta básica" e as possíveis contribuições de cada uma das disciplinas no desenvolvimento da atividade.

No início de dezembro, a professora de matemática apresentou aos alunos os conteúdos que seriam trabalhados no quarto bimestre e, em seguida, propôs o trabalho interdisciplinar sobre o "O custo da cesta básica na cidade de Colorado do Oeste". Nesse momento, foi feita a explanação de como seria desenvolvida a pesquisa, suas etapas, a participação de cada aluno, a forma como seriam avaliados no decorrer do trabalho, a contribuição da professora de geografia e a significância do trabalho para a comunidade local, já que o DIEESE (Departamento Intersindical de Estatística e Estudos SócioEconômicos) não realiza pesquisa nesse estado da União (DIEESE, 1993). Ao longo das 


\section{SOUSA; ULIANA (2012)}

explicações dadas pela professora, o tempo verbal foi o futuro do pretérito, a fim de reafirmar que a possibilidade de realização de tal atividade dependeria do aceite de todos.

Expressões como: "vocês fariam assim"; "os dados seriam organizados dessa maneira" chamaram a atenção de um aluno que a questionou: "Professora, por que a senhora fala "se a gente for realizar", a senhora acha que a pesquisa não vai dar certo?"

A professora explicou, então, que o trabalho só seria produtivo e dinâmico se eles se envolvessem, "comprassem a ideia" e que a realização do mesmo iria depender da vontade da turma. Nesse momento, os alunos manifestaram-se favoráveis à realização do trabalho.

\subsection{Interação com o tema}

A segunda etapa da atividade visou a inteirar os alunos sobre a temática do trabalho. Nessa etapa, a professora de geografia tomou a frente das atividades. Os 29 alunos foram divididos em cinco grupos, em seguida, foi escolhido um representante de cada grupo. Os cinco representantes passaram a compor um grupo de estudo que, em horário extraclasse, reunir-se-iam para ler textos sobre a temática. Orientados pela professora de geografia, esses alunos leram três artigos científicos e depois, durante dois encontros de uma hora cada um, realizaram discussões sobre a questão da fome, a história da cesta básica e do salário mínimo em nosso país e também a respeito dos itens que compõem a cesta básica das diferentes regiões.

$\mathrm{Na}$ sequência, durante uma aula de matemática em que estavam presentes as duas professoras, os cincos alunos do grupo de estudo socializaram com a turma o que estudaram sobre a temática da cesta básica. Os alunos não participantes do grupo de estudo fizeram alguns questionamentos; a discussão fluiu e as professoras participaram ora ajudando a responder os questionamentos, ora levantando outros pontos para a discussão. Todos os alunos se envolveram na discussão, uns de forma mais participativa, outros menos.

\subsection{Coleta e organização dos dados}

Essa etapa teve início na aula seguinte à socialização da temática com a turma. A professora de matemática havia recém começado o estudo a respeito de noções de estatística. Assim, foram apresentadas aos alunos as orientações metodológicas de coleta de dados do DIEESE: devem-se coletar os três menores preços de cada item em três supermercados de maior circulação da cidade ou região na qual se deseja calcular o custo da cesta básica (DIEESE, 1993).

Inicialmente, o desejo era apenas calcular o custo da cesta básica na cidade de Colorado do Oeste, mas como era período de recesso das festas de final de ano, os alunos iriam para as casas de seus pais, em diferentes municípios do Estado, eles sugeriram fazer a coleta em cinco cidades do Estado de Rondônia: Costa Marques, Buritis, Cerejeiras, Porto Velho e Colorado do Oeste. Segundo um dos alunos, assim eles poderiam comparar os preços praticados em diferentes supermercados de diferentes cidades do Estado.

Visando a analisar a origem dos produtos comercializados nas cidades de Rondônia, a professora de geografia solicitou que durante a coleta dos preços fosse anotada a origem (local de produção) dos itens que compõem a cesta básica. A professora de matemática, objetivando organizar a coleta de dados, elaborou um 


\section{SOUSA; ULIANA (2012)}

formulário com os itens e campos para eles anotarem os nomes, o custo e a origem dos produtos. A Instituição de Ensino expediu um documento informando que o estudo tinha fins puramente acadêmicos para que os alunos apresentassem nos estabelecimentos comerciais em que realizariam a coleta de dados.

$\mathrm{Na}$ primeira semana de janeiro de 2012, em aula realizada no laboratório de Informática, os alunos iniciaram a organização e o tratamento estatístico dos dados coletados. Utilizando o programa Microsoft Excel, cada grupo organizou os dados coletados, calculou a média aritmética do custo de cada item, a moda, a mediana, o desvio padrão, a amplitude total dos dados de cada supermercado pesquisado e depois aglomerou esses dados, a fim de encontrar o custo médio da cesta básica em cada cidade. De posse do valor médio da cesta básica, em cinco cidades com diferentes formações política e social, além de localizarem-se em pontos diferentes do Estado de Rondônia, foi possível calcular o custo médio da cesta básica no referido Estado. Isso foi obtido a partir da socialização dos dados coletados entre todos os grupos.

\subsection{Modelos matemáticos e análise crítica da solução}

Segundo Biembengut (2004), modelo matemático é um conjunto de símbolos e relações matemáticas que traduzem, de alguma forma, um fenômeno em questão levando à solução de um problema ou permitindo a dedução de sua solução. Nesta atividade de modelagem, os modelos que melhor contemplaram a situação-problema de estudo foram tabelas e gráficos.

Os dados foram organizados e apresentados em tabelas e em gráficos de coluna e de setores. Depois que os grupos encontraram o custo médio da cesta básica nas cidades onde foram coletados os dados, verificaram também o custo médio no Estado de Rondônia. Esses dados foram organizados em uma tabela (Tabela 1) com o objetivo de facilitar a comparação dos preços dos itens nas diferentes cidades e no Estado de Rondônia.

Tabela 1 - Custo da cesta básica em Rondônia - dezembro de 2011.

\begin{tabular}{|c|c|c|c|c|c|c|c|}
\hline $\begin{array}{c}\text { Itens da cesta } \\
\text { básica }\end{array}$ & $\begin{array}{c}\text { Quantidad } \\
e\end{array}$ & Buritis & Cerejeiras & Porto Velho & Costa Marques & $\begin{array}{l}\text { Colorado do } \\
\text { Oeste }\end{array}$ & $\begin{array}{c}\text { Rondôni } \\
\text { a }\end{array}$ \\
\hline Carne (kg) & 4,5 & 49,485 & 50,705 & 54,45 & 50,21 & 49,1 & 50,79 \\
\hline Leite (I) & 6 & 13,11 & 13,86 & 12,08 & 15,44 & 14,34 & 13,76 \\
\hline Feijão (kg) & 4,5 & 19,01 & 16,74 & 13,10 & 17,07 & 18,61 & 16,90 \\
\hline Arroz (kg) & 3,6 & 5,60 & 6,35 & 11,40 & 6,18 & 6,82 & 7,27 \\
\hline Farinha $(\mathrm{kg})$ & 3 & 9,63 & 7,09 & 5,74 & 10,69 & 12,22 & 9,07 \\
\hline Tomate (kg) & 12 & 32,91 & 33,72 & 34,64 & 39,78 & 45,6 & 37,33 \\
\hline Pão Francês (kg) & 6 & 22,99 & 34,9 & 40,7 & 33,72 & 35,4 & 33,54 \\
\hline Café em pó (kg) & 0,3 & 3,58 & 4,24 & 1,65 & 1,74 & 4,17 & 3,08 \\
\hline Banana unidade & 90 & 19,39 & 26,98 & 23,02 & 24,6 & 29,02 & 24,60 \\
\hline Açúcar (kg) & 3 & 5,32 & 8,76 & 7,75 & 11,79 & 9,64 & 8,65 \\
\hline Óleo (ml) & 750 & 2,28 & 2,76 & 2,34 & 2,34 & 2,60 & 2,47 \\
\hline Manteiga (kg) & 0,75 & 12,82 & 5,13 & 5,59 & 5,72 & 3,94 & 6,64 \\
\hline Custo da cesta & & 196,16 & 211,26 & 212,50 & 219,33 & 231,49 & 214,15 \\
\hline
\end{tabular}

Fonte: Dados da pesquisa

Dando continuidade à atividade, os grupos organizaram tabelas e, posteriormente, elaboraram gráficos de setores com os dados que coletaram sobre a origem (local de produção) dos itens da cesta básica. Os gráficos da origem dos itens 


\section{SOUSA; ULIANA (2012)}

que compõem a cesta básica motivaram e alimentaram uma calorosa discussão acerca das variáveis: custo e origem dos produtos. A cidade pesquisada que apresentou menor custo da cesta básica foi Buritis. Constatou-se que $79 \%$ dos produtos que compõem a cesta básica, neste município, são oriundos do próprio Estado. Por outro lado, a cidade de Colorado do Oeste apresentou o maior valor da cesta básica e somente $23 \%$ dos produtos comercializados nesse município são produzidos no Estado. Tais dados podem ser verificados nos gráficos 1 e 2 .

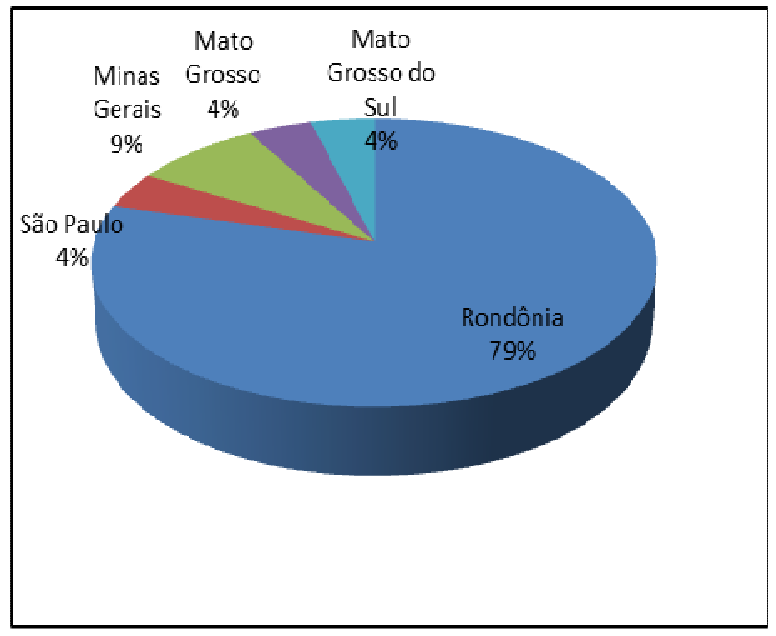

Gráfico 1 - Origem dos produtos da cesta básica na cidade de Buritis

Fonte: Dados da pesquisa

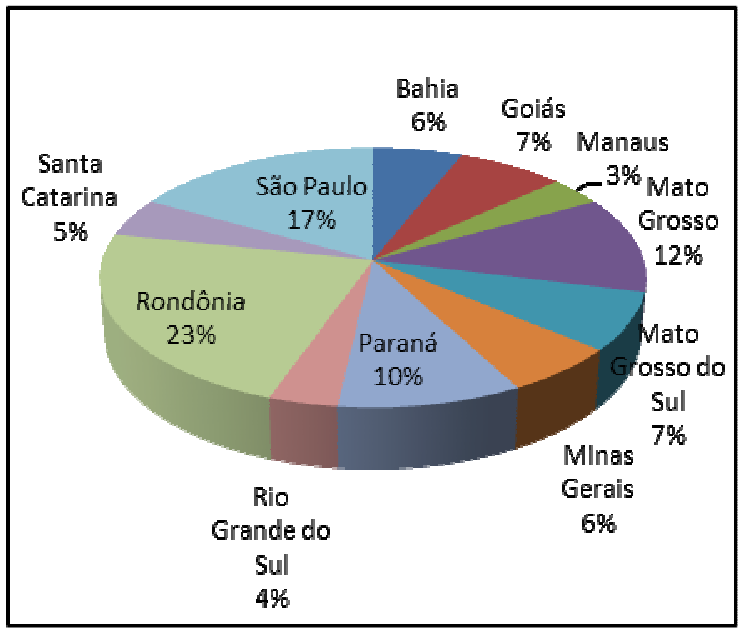

Gráfico 2 - Origem dos produtos da cesta básica na cidade de Colorado do Oeste

Fonte: Dados da pesquisa

Os dados organizados em tabelas e gráficos continuaram a subsidiar as aulas de estatística e possibilitaram explorar alguns tópicos de matemática financeira. Visando promover a investigação e a discussão dos dados discretos, coletados e trabalhados nas aulas, foi proposto aos grupos um questionário. Foi pedido Sendo solicitado para os-aos alunos que observassem e calculassem o percentual de variação de preço de um supermercado para outro e de uma cidade para outra. Também foi solicitado que verificassem quantas horas de trabalho uma família, que ganha um salário mínimo, precisa destinar para adquirir uma cesta básica. Além disso, os estudantes deveriam diagnosticar o índice que determina a origem (local de produção) dos itens que compõem a cesta básica da região. Após, deveriam comparar o custo da cesta básica local com o custo da cesta básica nas demais regiões, de acordo com os dados do DIEESE.

No cenário para investigações, de acordo com Skovsmose (2001), as indagações feitas aos alunos possibilitam que estes pesquisem os dados coletados por meio de manipulações das informações já existentes e isso irá desencadear outras reflexões acerca dos temas e conteúdos tratados. Durante duas aulas, os grupos mobilizaram-se para responder o questionário. Para isso necessitaram rever ou estudar tópicos da matemática financeira. Depois de concluída essa tarefa, a professora solicitou que os grupos organizassem, em um horário extraclasse, um texto coerente intercalando as tabelas e os gráficos com as respostas do questionário.

Os cinco grupos produziram um texto utilizando os gráficos e tabelas que estavam de acordo com os padrões normativos da estatística. Os alunos identificaram e 


\section{SOUSA; ULIANA (2012)}

interpretaram a moda, a média, a mediana, a amplitude e o desvio padrão dos dados coletados. Também correlacionaram valores referentes ao custo da cesta básica ao do salário mínimo, hora de trabalho mensal destinada à aquisição de uma cesta básica e custo desta em família com maior número de pessoas.

Outro gráfico que merece destaque é o que permite a comparação do custo da cesta básica de Colorado do Oeste, com o de Rondônia e com os custos das localidades onde são realizadas pesquisas mensais pelo DIEESE.

Gráfico 3 - Preço médio da cesta básica na cidade de Colorado do Oeste, no Estado de Rondônia e localidades onde o DIEESE realiza pesquisa - Dezembro de 2011

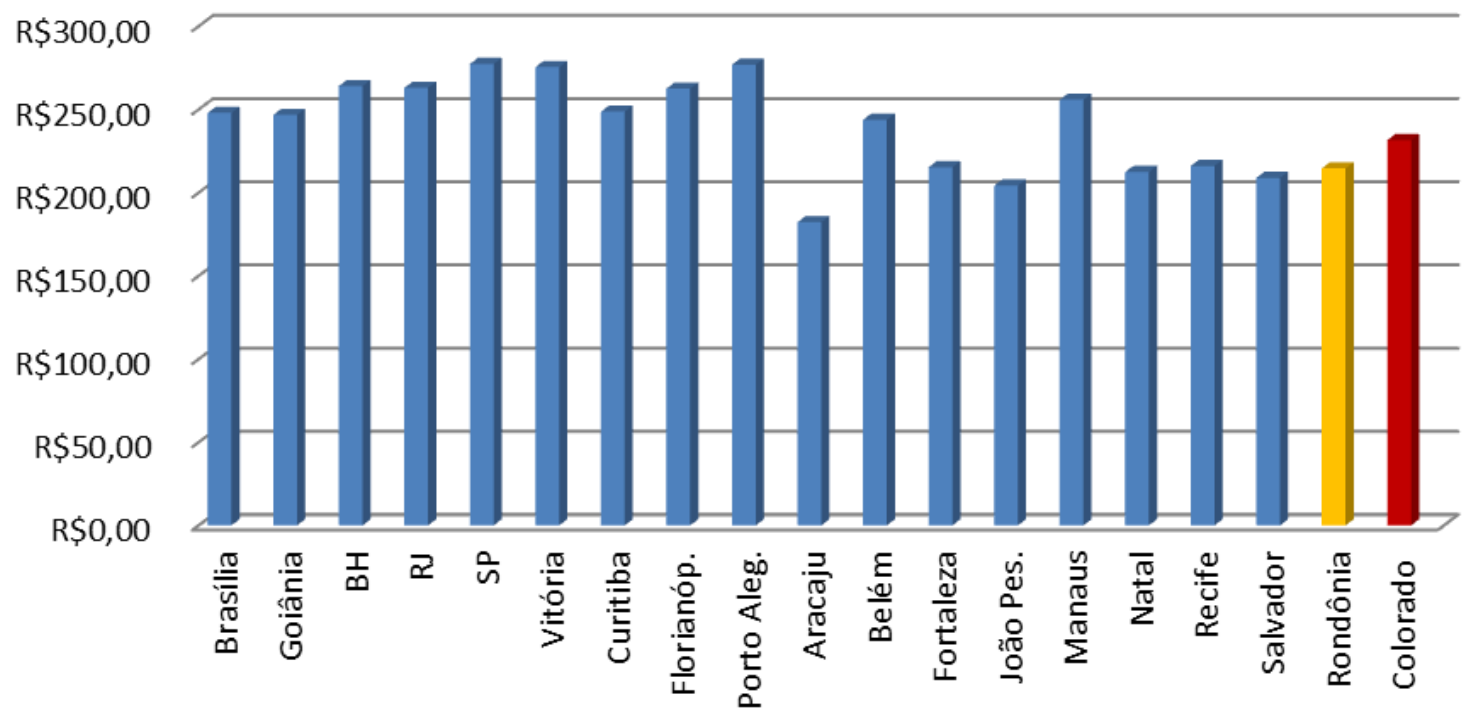

Fonte: Dados da pesquisa e do DIEESE

Com o objetivo de mostrar aos alunos que é possível adquirir uma cesta básica com preços mais acessíveis, foi requisitado que cada grupo elaborasse uma tabela com os itens de menores preços encontrados na cidade em que realizou a coleta.

Após o término do trabalho, os resultados foram divulgados para toda a comunidade escolar através de apresentação de slides e distribuição de folder pelos alunos envolvidos na atividade. A divulgação dos resultados deixou os alunos empolgados; notava-se um orgulho pelo fato deles serem os responsáveis pelo estudo e resultados apresentados em tabelas e gráficos. A socialização ocorreu durante um momento cívico que, tradicionalmente, acontece às sextas-feiras, no período matutino, reunindo toda a comunidade escolar para cantar o hino nacional e fazer o hasteamento das bandeiras. Esse momento também é utilizado pelos alunos para divulgarem os resultados dos trabalhos por eles produzidos.

\section{Conclusão}




\section{SOUSA; ULIANA (2012)}

Este trabalho possibilitou conhecer o custo médio da cesta básica em algumas cidades do Estado de Rondônia, além de trazer várias informações úteis à população destas cidades. Esse fato remete aos princípios educacionais que vêm sendo defendidos e orientados pelos Programas Curriculares Nacionais para o Ensino Médio que enfatizam a necessidade de promover um ensino mais contextualizado e interdisciplinar.

Além dos dados numéricos obtidos, este trabalho também possibilitou o processo de construção de conhecimentos referentes aos conteúdos da matemática e da geografia por parte dos alunos que se envolveram em todas as etapas de desenvolvimento dessa pesquisa, desde a leitura dos artigos científicos, divisão de tarefas por grupo, coleta de dados, escolha de locais de coleta, estudo de metodologia de coleta de dados segundo a DIEESE, organização e tabulação dos dados no Microsoft Excel e análise/discussão dos dados.

\section{Referências}

ALMEIDA, Lourdes Maria Werle; VERTUAN, Rodolfo Eduardo. Discussões sobre "como fazer" Modelagem Matemática na sala de aula. In: ALMEIDA, Lourdes Maria Werle; ARAÚJO, Jussara de Loiola; BISOGNIN, Eleni (Org.). Práticas de Modelagem Matemática na Educação Matemática. Londrina: Eduel, 2011.

BARBOSA, Joney Cerqueira. Modelagem Matemática: O que é? Por que? Como? Veritati, Feira de Santana, n. 4, p. 73- 80, 2004.

BARROS, Joel. $O$ que é Modelagem Matemática? Disponível em: <http://joelbarrosmatematica.blogspot.com/2009/04/o-que-e-modelagem-matematica>. Acesso em: 23 de out. de 2010.

BASSANEZI, Rodney Carlos. Ensino-aprendizagem com modelagem matemática: uma nova estratégia. 3. ed. São Paulo: Contexto, 2006.

BIEMBENGUT, Maria Salett. Modelagem Matemática \& implicações no Ensino e na Aprendizagem de Matemática. 2. ed. Blumenau: Edfurb, 2004.

30 Anos de Modelagem Matemática na Educação Brasileira: das

propostas primeiras às propostas atuais. ALEXANDRIA Revista de Educação em Ciência e Tecnologia, v.2, n.2, p.7-32, jul. 2009.

BIEMBENGUT, Maria Salett; HEIN, Nelson. Modelagem matemática no ensino. 4. ed. São Paulo: Contexto, 2007.

BRASIL. Ministério da Educação. Secretária de Educação Básica. Orientações curriculares para o ensino médio: ciência da natureza, matemática e suas tecnologias. Brasília, v. 2, 2006. 136 p.

BRASIL. Ministério da Educação. Parâmetros curriculares nacionais: Matemática. Brasília, v. 3, 1997. 


\section{SOUSA; ULIANA (2012)}

DIEESE. Cesta Básica: metodologia. São Paulo, 1993. Disponível em:

<http://www.dieese.org.br/rel/rac/metodologia.pdf>. Acesso em: 20 dez. 2011.

DRUCK, Sueli. O ensino da Matemática no Brasil.2008. Disponível em:

$<$ http://cienciahoje.uol.com.br/podcasts/009-O-ensino-da-matematica-no-

Brasil.mp3/view>. Acesso em: 20 mai. 2012.

GAZIRE, Eliane Scheid. O não resgate das geometrias. 2000. 238f. Tese (Doutorado) Faculdade de Educação, Universidade Estadual de Campinas, , Campinas, 2000.

NERES, Raimundo Luna. Movimento da Matemática Moderna no Brasil. São Luís:

EDUFMA, 2011.

PEREZ, Geraldo. Prática reflexiva do professor de matemática. In: BICUDO, M. A. V. \& BORBA, Marcelo de Carvalho. (Org). Educação matemática: pesquisa em movimento. São Paulo: Cortez, 2004.

SALLA, Fernanda. Toda a atenção para a Neurociência. Revista Nova Escola. São Paulo, ano XXVII, n. 253, jun. 2012.

SKOVSMOSE, Ole. Educação Matemática Crítica: a questão da democracia. 4. ed.

Campinas, SP: Papirus, 2001. 